\title{
烯酮亚胺盐化学的研究进展
}

\author{
李晓锦 ${ }^{a}$ 孙 艳 ${ }^{a}$ 张 䂞*,a 彭 勃*,a,b
}

( ${ }^{a}$ 浙江师范大学化学与生命科学学院 金华 321004)

( $b$ 大连理工大学精细化工国家重点实验室 大连 116024)

\begin{abstract}
摘要 烯酮亚胺盐是一类独特的杂联烯, 高亲电性以及累积二烯的结构特点赋予了烯酮亚胺盐反应的多样性. 介绍了 非金属亲电试剂活化酰胺或炔酰胺制备的烯酮亚胺盐. 该类烯酮亚胺盐与不同种类的亲核试剂主要发生亲电加成反 应、亲电取代反应、环加成反应. 近年来, 烯酮亚胺盐参与的亲电重排反应得到较大发展, 所以将对这一进展作重点介 绍.
\end{abstract}

关键词 烯酮亚胺盐; 亲电重排; 亲电取代; 环加成反应

\section{Recent Progress in the Chemistry of Keteniminium Salts}

\author{
Li, Xiaojin ${ }^{a}$ Sun, Yan $^{a} \quad$ Zhang, Lei*,a Peng, Bo*,a,b \\ $\left({ }^{a}\right.$ College of Chemistry and Life Sciences, Zhejiang Normal University, Jinhua 321004) \\ ( ${ }^{b}$ State Key Laboratory of Fine Chemicals, Dalian University of Technology, Dalian 116024)
}

\begin{abstract}
Keteniminium salts are unique heteroallenes. The high electrophility and cumulative double bonds render them versatile reactivity. This paper describes the keteniminium salts formed by electrophilic activation of amides or ynamides with non-metal electrophilic reagents. These keteniminium salts mainly undergo electrophilic addition, eletrophilic substitution, cycloaddition with various nucleophiles. In past few years, the study of keteniminium induced electrophilic rearrangement has progressed rapidly. The newly developed rearrangement transformations are also described here.

Keywords keteniminium salts; electrophilic rearrangement; electrophilic substitution; cycloaddtion
\end{abstract}

累积二烯是一类结构特殊的有机官能团, 两组相互 垂直的 $\pi$ 键使该类化合物常常表现出异于普通单烯烃的 反应特性 ${ }^{[1]}$. 作为氮杂联烯, 烯酮亚胺(ketenimine)具有 $\mathrm{C}_{\beta}=\mathrm{C}_{\alpha}=\mathrm{N}$ 的累积二烯结构, 其中间 $\mathrm{C}_{\alpha}$ 为 $\mathrm{sp}$ 杂化碳, 通 常比亚胺碳有着更高的亲电性, 而两边的 $\mathrm{C}_{\beta}$ 和 $\mathrm{N}$ 表现 出亲核性, 因此烯酮亚胺盐展现出多样的反应性. 不难 理解, 自 1919 年 Staudinger 等 ${ }^{[2]}$ 成功合成烯酮亚胺后, 化学家对烯酮亚胺结构及反应性研究投入了极大的热 情, 实现了烯酮亚胺参与的多种类型反应, 包括亲核加 成反应 ${ }^{[3]}$ 、自由基加成反应 ${ }^{[4]}$ 、环加成反应 ${ }^{[5]}$ 、电环化 ${ }^{[6]}$ 和 $\delta$ 键重排反应 ${ }^{[7]}$. 与烯酮亚胺相比较, 在烯酮亚胺盐 (keteniminium)中, 亚胺盐相对亚胺有着更高的亲电性, 常被理解为一类不稳定的中间体, 以至阻碍了烯酮亚胺
盐化学的发展. 但研究表明, 烯酮亚胺盐的稳定性并不 像想象中那么差. 如烯酮亚胺盐在与烯烃的环加成反应 中表现得比烯酮更稳定，自身不易聚合、反应选择性更 ${ }^{\text {高 }}{ }^{[8]}$. 近年来, 围绕这种具有高亲电性且有一定稳定性 的氮杂联烯的反应研究逐渐增多. Hsung ${ }^{[9]}$ 和 Maulide 等 ${ }^{[10]}$ 分别从不同角度对烯酮亚胺盐化学进行了综述评 论. 本文将简单介绍烯酮亚胺盐化学相关反应的发展脉 络, 重点解读其最新进展.

烯酮亚胺盐通常可以由酰胺或炔胺制备. 其中, 酰 胺制备烯酮亚胺盐有两种方式(Scheme 1). (1)对于 $\alpha$ 位 含有取代基的酰胺，通常以草酰氯为亲电试剂，将酰胺 转化成氯代亚胺阳离子, 再引入三乙胺脱除亚胺阳离子 的 $\alpha$ 氢得到 $\alpha$ 氯代烯胺，最后用路易斯酸如 $\mathrm{AlCl}_{3} 、 \mathrm{ZnCl}_{2}$

\footnotetext{
*E-mail: pengbo@zjnu.cn; lzhang@zjnu.cn

Received May 31, 2016; revised August 16, 2016; published online August 22, 2016.

Project supported by the National Natural Science Foundation of China (No. 21502171), the State Key Laboratory of Fine Chemicals (No. KF1512) and the Educational Commission of Zhejiang Province (No. Y201328123)

国家自然科学基金(No. 21502171)、大连理工大学精细化工国家重点实验室开放课题基金(No. KF1512)、浙江省教育厅科研(No. Y201328123)资助项 目.
} 
<smiles>[R]CC(=O)N([R])C(=O)C[R]</smiles>

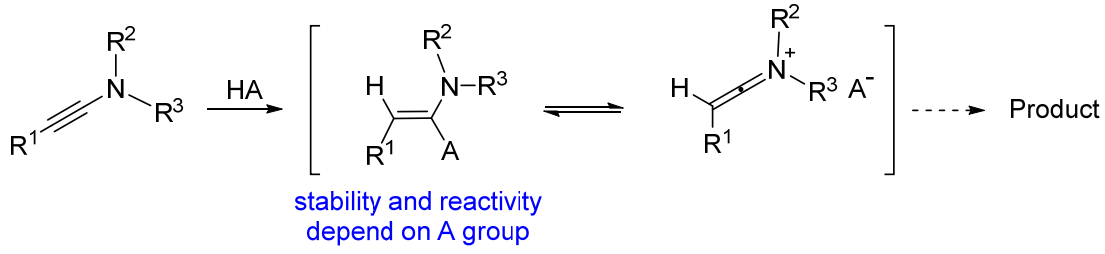

图式 1 烯酮亚胺盐的生成方式

Scheme 1 Generation of keteniminium salts

活化氯代烯胺，促进烯酮亚胺盐的生成 ${ }^{[11]}$; 值得注意的 是, 此方法合成的 $\alpha$ 氯代烯胺通常比较稳定, 可以进行 纯化. (2)以 $\alpha$ 位没有取代基的酰胺为原料, 可使用三氟 甲磺酸䣶为亲电试剂, 辅以吡啶衍生物作碱, 将酰胺转 换为烯胺中间体. 该中间体通常不稳定, 会进一步脱除 吡啶衍生物形成烯酮亚胺盐 ${ }^{[12]}$. 除此之外, 也可以使用 质子酸 (HA) 与炔胺反应, 直接得到烯胺 ${ }^{[13]}$. 该烯胺的稳 定性取决于酸的种类, 如以三氟甲磺酸活化炔胺, 得到 的不稳定烯胺中间体, 容易转换为烯酮亚胺盐, 而以苯 甲酸活化炔胺, 得到的烯胺比较稳定. 可以对其进行分 离纯化, 但难以转换为相应的烯酮亚胺盐. 需要指出的 是, 炔酰胺也可与过渡金属作用, 形成过渡金属取代的 烯酮亚胺盐, 相关研究已有大量综述报道, 本文将不涉 及这部分内容.

以上述不同方式获得的烯酮亚胺盐, 具有烯酮亚胺 类似的反应性, $\alpha$ 碳有很强的亲电性, $\beta$ 碳又有一定的亲 核性, 因而烯酮亚胺盐可视为 1,2-偶极的反应单元, 可 分步与亲核试剂、亲电试剂反应(Scheme 2). 烯酮亚胺 盐参与的反应类型包括亲电加成、亲电取代、环加成反 应、亲电重排反应(Scheme 3). 本文将对这四类反应近 年来的发展进行综合评述.

\section{1 亲电加成反应}

1970 年, Ghosez 等 ${ }^{[14]}$ 首次提出烯酮亚胺盐参与的 亲电加成反应(Scheme 4), 发现亲核试剂叠氮化钠可与 烯酮亚胺盐反应制备叠氮化的烯胺 2 , 随后分子内关环 得到氮杂环丙烯 3 , 并释放氮气. 此后, 对该类反应的 研究鲜有报道, 直到 2008 年 Oshima 等 ${ }^{[15]}$ 发现炔酰胺与 二苯基二硫代磷酸反应可高区域选择性和立体选择性 地生成 $E$ 式的 $N, S$-烯酮 6 (Eq. 1). 选择性地生成 $E$ 式产 物是由于亲核试剂选择空间位阻较小的一端进攻烯酮 亚胺盐所致.

该反应条件温和, 不需任何催化剂, 在室温条件下 反应 $1 \mathrm{~h}$ 即可得到较高收率的加成产物 $\mathbf{6}$.

毕锡和等 ${ }^{[16]}$ 报道了无金属催化条件下炔酰胺水合 反应以及与羧酸的加成反应(Scheme 5). 两个反应都由 质子酸亲电活化炔酰胺形成烯酮亚胺盐中间体, 随后体 系中水或者羧酸根进攻烯酮亚胺盐得到官能团化的酰 胺产物 8 和 $\alpha$-酰氧基取代的烯酰胺产物 9. 与先前 Oshima 等的发现相似, 水或羧酸根对烯酮亚胺盐的加 成也具有高度立体选择性, 专一形成 $E$ 式加成产物.<smiles>[R]CC(CN)(CN)[N+]([R])([R])C[R]</smiles>

图式 2 烯酮亚胺盐的通常反应性

Scheme 2 General reactivity of keteniminium salts 

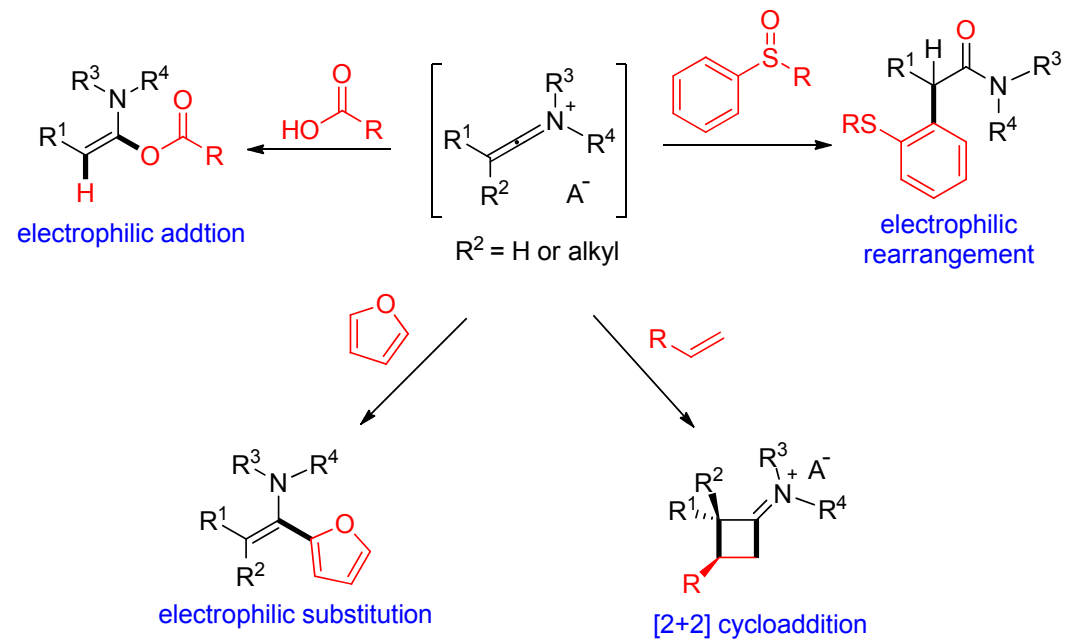

图式 3 烯酮亚胺盐参与的反应类型

Scheme 3 Keteniminium involved transformations

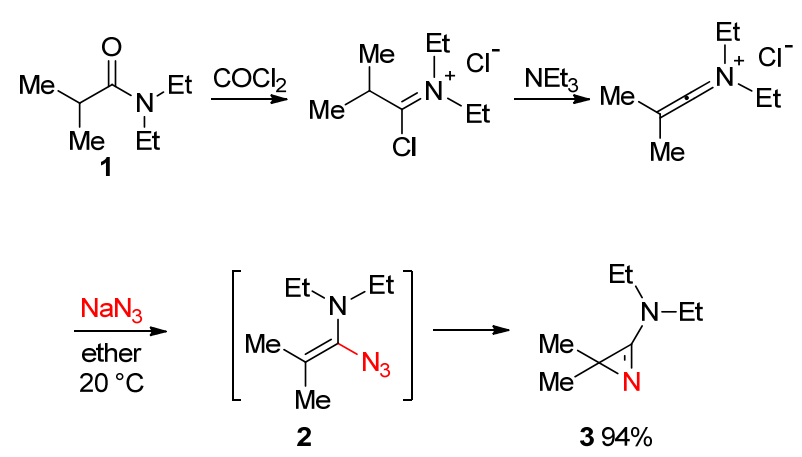

图式 4 烯酮亚胺盐与叠氮化钠反应

Scheme 4 Reaction of keteniminium salts with sodium azide<smiles>[R]C/C(SP(=S)(c1ccccc1)c1ccccc1)=C(\[R])N([R])C(C)(C)C</smiles>

6 $63 \% \sim 97 \%$

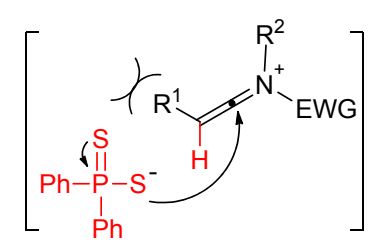

2012 年, Thibaudeau 和 Evano 等 ${ }^{[17]}$ 报道了一种炔酰 胺的氢氟化方法, 制备 $\alpha$-氟代烯酰胺(Eq. 2). 由于需要 使用无水氢氟酸, 反应对于含有酸敏感的基团或手性炔 酰胺底物不太适用, 且操作较为危险, 限制了该方法的 应用. 2015 年, 该课题组 ${ }^{[18]}$ 又报道了炔酰胺与氟化氢/吡 啶(质量比为 70/30)作用, 化学及立体选择性地合成 $\alpha$ 氟代烯酰胺(Conditions B). 该方法的适用性得到很大的 提高, 对含有芳基、烷基、磺酰胺基、氨基甲酸酯基及

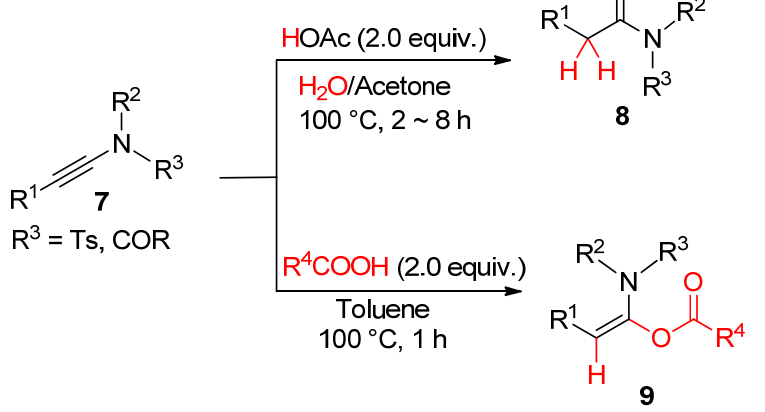

图式 5 炔酰胺的水合及加氢酰氧化反应

Scheme 5 Hydration and hydroacyloxylation reactions of ynamides

酰胺基的炔酰胺化合物都适用. 与先前的发现类似, 氟 原子选择位阻较小的一端进攻烯酮亚胺盐, 产物以 $E$ 式 的 $\alpha$-氟代烯酰胺为主(如 $\mathbf{B}_{1}$ ). 但对于吡啶取代的炔酰胺 $10 \mathrm{c}$, 吡啶氮原子与氢氟酸形成分子间氢键, 促使氟原 子从烯烃双键的同面进攻, 产物以 $Z$ 式的 $\alpha$-氟代烯酰胺 为主(如 $\left.\mathbf{B}_{2}\right)$ (图 1).

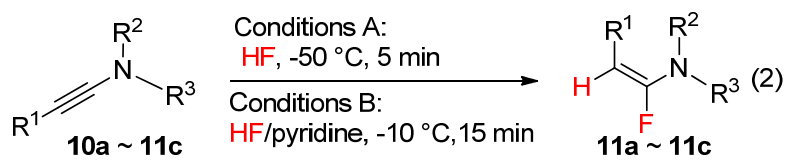<smiles>F/C(=C/Pc1ccccc1)N([As])Cc1ccccc1</smiles>

A: $96 \%(E / Z=99 / 1)$

B: $86 \%(E / Z=98 / 2)$

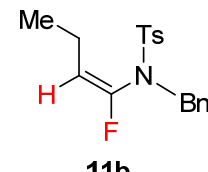

11b

A: $52 \%(E / Z=93 / 7) \quad$ A: $80 \%(E / Z=32 / 68)$ B: $42 \%(E / Z=91 / 9) \quad$ B: $84 \%(E / Z=18 / 82)$ 


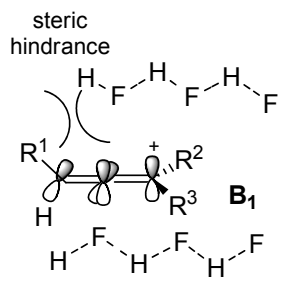

favors $(E)$

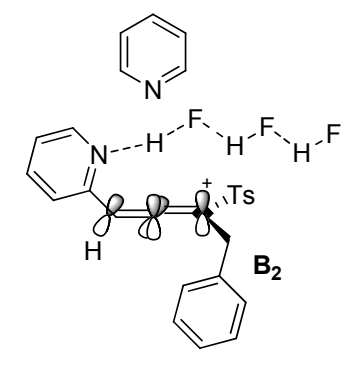

favors $(Z)$

图 1 炔酰胺氢氟化的立体选择性解释

Figure 1 Illustration of stereoselectivity in hydrofluorination of ynamides

近期, Maulide 等 ${ }^{[19]}$ 发现酰胺在三氟甲磺酸酐/2-氟 代吡啶亲电体系下形成烯酮亚胺盐, 能与叠氮化合物发 生亲电加成制备 $\alpha$-氨基酰胺化合物 17 ，从而开拓了烯酮 亚胺盐与叠氮化合物的新反应类型(Scheme 6). 该反应 条件温和，且化学选择性非常好，酯基或崖基不会对该 反应产生影响. Maulide 等 ${ }^{[20]}$ 还发现炔酰胺在 Brønsted 酸作用下形成的烯酮亚胺盐也能与叠氮化合物反应，有 意思的是，反应并没有形成 $\alpha$-氨基酰胺化合物，而是通 过一系列杂环关环、开环过程制备了烷胺化啞唑酮 23 (Scheme 7).

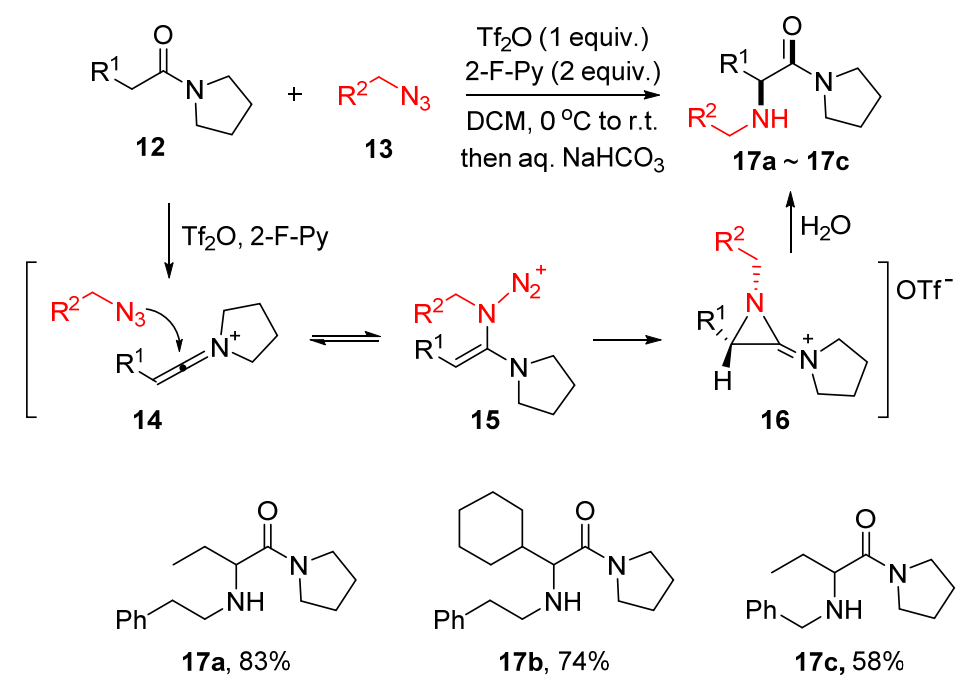

图式 6 酰胺化合物的 $\alpha$-氨基化反应

Scheme 6 Amination of amides with azides

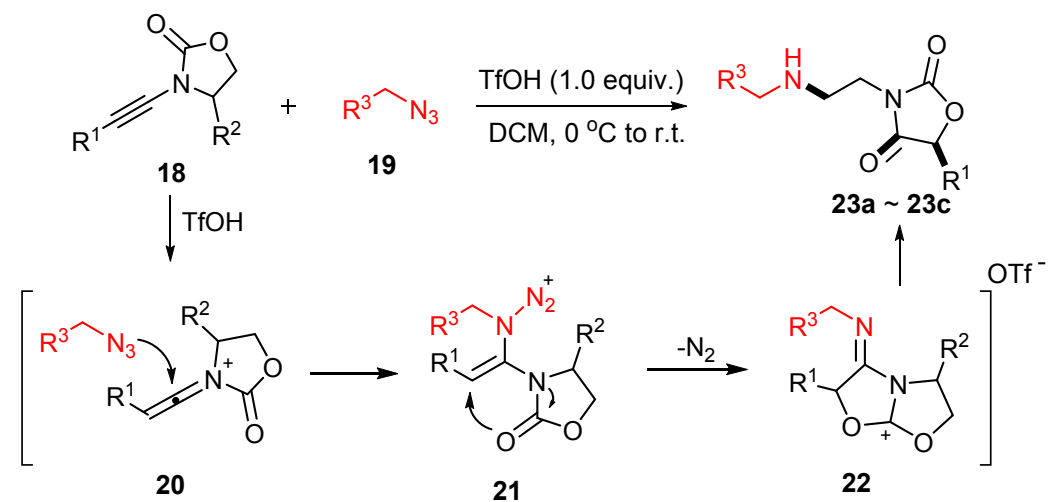<smiles>CC(C)[C@H](CNCCc1ccccc1)N1C(=O)O[C@@H](c2ccccc2)C1=O</smiles>

$72 \%, d r=85: 15$

图式 7 质子酸催化的炔酰胺与叠氮化合物的反应

Scheme 7 Reactivity of ynamides and azides under Brønsted acid catalysis 
除杂原子以外, 氢负离子也可以对烯酮亚胺盐进行 亲核加成. Thibaudeau 与 Evano 等 ${ }^{[21]}$ 在研究炔酰胺氢氟 化的过程中意外发现, 芳基炔酰胺 24 在氢氟化反应条 件下给出了含多重碳环骨架的化合物 25 (Eq. 3). 其他 的强质子酸如三氟甲磺酸(HOTf)或双三氟甲基磺酰亚

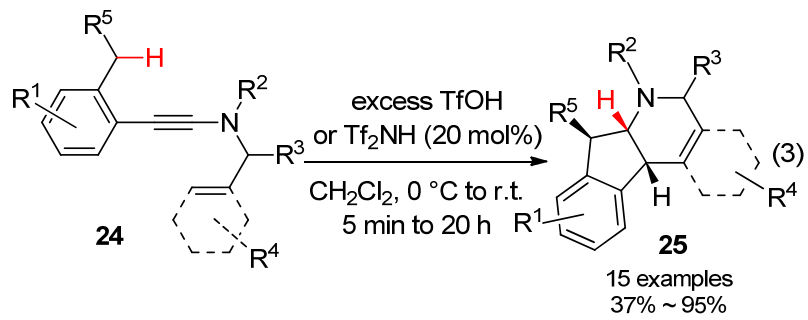

胺酰胺反应形成烯酮亚胺盐 26 , 随后该高亲电的烯酮 亚胺盐引发分子内 $[1,5]$-氢迁移形成亚胺阳离子中间体 27, 其共振式为中间体 28, 再经 $4 \pi$-顺旋电环化(Nazarov 型电环化)、分子内亲电环化得到产物 25 (Scheme 8).

最近, Evano 等 ${ }^{[22]}$ 在上述工作基础上，通过巧妙设 计炔酰胺底物, 再次利用烯酮亚胺盐的高亲电性来引发 分子内的 [1,5]-氢迁移, 形成的烯胺中间体 32, 再经过 分子内亲电环化制备了哌啶类似物 34 (Scheme 9). 值得 注意, 且令人惊讶的是该反应可在一 $60{ }^{\circ} \mathrm{C}$ 甚至更低温 度下进行, 实现非活化 $\mathrm{sp}^{3}-\mathrm{C}-\mathrm{H}$ 键的活化官能团化.

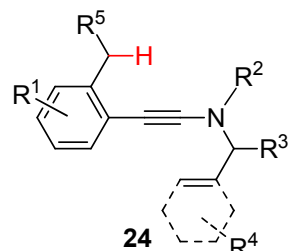<smiles>CC(C)(C)C</smiles>

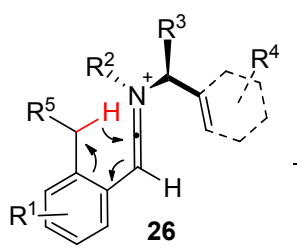<smiles>COCCO</smiles>

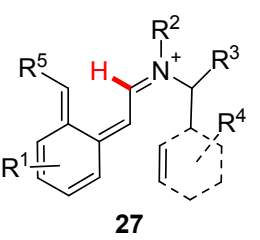

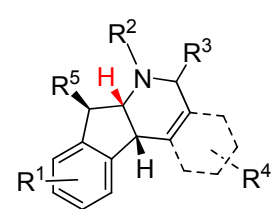<smiles>[CH+]CC</smiles>

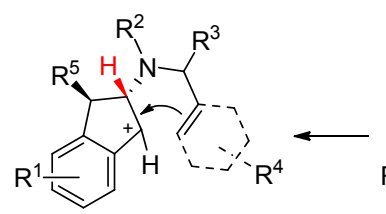

29

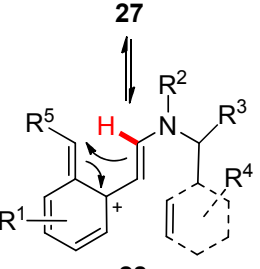

28

图式 8 炔酰胺多环环化反应的可能机理

Scheme 8 Proposed mechanism for the cationic polycyclization<smiles>[R]C([R])C([R])C([R])C([R])N(C#[R])C#[R]</smiles>

$$
\begin{gathered}
\underset{\mathrm{CH}_{2} \mathrm{Cl}_{2},-60^{\circ} \mathrm{C}}{15 \mathrm{~min}} \\
\stackrel{\mathrm{TfOH}}{(5.0 \text { equiv.) }}
\end{gathered}
$$<smiles>[R]C1C([R])C([R])([R19])C([R])C([R])N1C(C)C</smiles>

$34 a \sim 34 d$<smiles>[CH+][CH-][IH+]</smiles><smiles>[R1]CN(C([R])=[W])C([R])C([R])C([R])([R])CC</smiles><smiles>[R]CC([R])([R])C([R])C([R])N(C)C=CC</smiles><smiles>[R]C1=[N+]([N+](=O)[O-])[C@@H](C)C([R])C([R])C1([R])[R]</smiles>

32

33<smiles>CC1(C)CCN([TeH])C=C1c1ccccc1</smiles><smiles>[3H]N1C=C(Cl)C(C)(C)CC1</smiles>

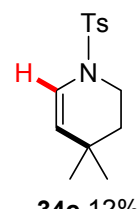

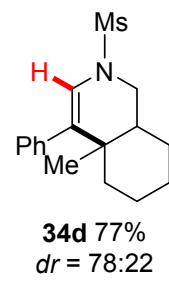

图式 9 烯酮亚胺盐引发的 1,5-H 迁移反应

Scheme 9 Keteniminium triggered 1,5-H shift reaction 


\section{2 亲电取代反应}

1972 年 $G h o s e z^{[23]}$ 提出以 $\alpha$-氯代烯胺为原料制备的 烯酮亚胺盐可与富电子芳烃发生亲电取代反应, 制备 $\alpha$ 芳基化的烯胺衍生物 37 (Scheme 10). 但文中他们并未 给出反应的具体条件和反应的产率. 此后烯酮亚胺盐的 分子间亲电取代反应鲜有报道. 直到 2005 年, Zhang ${ }^{[24]}$ 连续报道了双三氟甲基磺酰亚胺催化炔酰胺的氢芳化 反应，可高区域选择性和立体选择性地制备顺式的乙烯 基吡咯、呋喃及吲哚(Eq. 4).<smiles>[R]C([R])=C(Cl)N([R])[R1]</smiles>

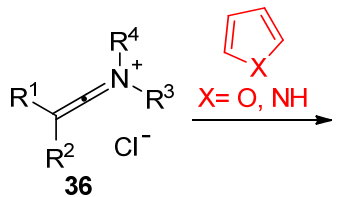<smiles>[R]/C(=C(\[R])N([R])[B])c1[X]ccc1</smiles>

图式 10 烯酮亚胺盐与吡咯、呋喃的亲电取代反应 Scheme 10 Electrophilic substitution of pyrroles or furans with keteniminium salts

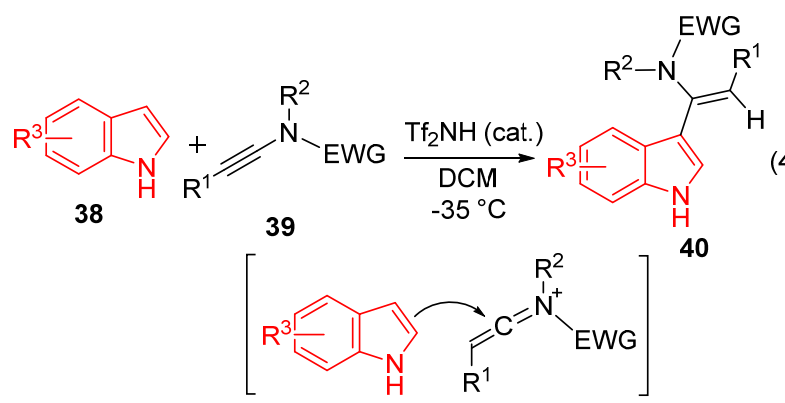

除上述分子间亲电取代反应外，烯酮亚胺盐的分子 内亲电取代反应也得到了很好的发展, 并被用来制备结 构各异的杂、碳环化合物. 其中, 1981 年, Ghosez 等 ${ }^{[25]}$ 尝试 $\beta$-芳硫基烯酤亚胺盐与环戊烯的 $[2+2]$ 环加成反应 中, 未观察到环加成产物的生成, 而是意外发现烯酮亚 胺盐进攻富电子的芳环生成 $\beta$-氨基苯并噻吩 42. 2005 年, Hsung 等 ${ }^{[26]}$ 报道了对硝基苯磺酸(PNBSA)催化的立 体选择性芳基一炔酰胺环化反应, 高效地合成了含氮杂 环的生物碱类化合物 44. 最近, De Mesmaeker ${ }^{[28]}$ 以酰胺 为原料制备烯酮亚胺盐, 引发分子内亲电环化反应, 成 功制备了一系列 3-氨基苯并噻吩衍生物 $46^{[27]}$ 以及 $\beta$-䒺 胺衍生物 48. 此外, Takasu 等 ${ }^{[29]}$ 利用同样策略开发了质 子酸催化的芳基一炔酰胺环化反应来构建喹啉衍生物 $\mathbf{5 0}$ 的方法(Scheme 11).

\section{3 [2+2]环加成反应}

烯酮亚胺盐参与的环加成反应, Snider ${ }^{[8]}$ 及 Maulide 等 ${ }^{[10]}$ 已作过相关综述. 在此, 我们选取该类反应较为重 要的发展节点, 简明扼要的阐述其发展历程, 总结此类 反应的规律和特点.
1981. Ghosez
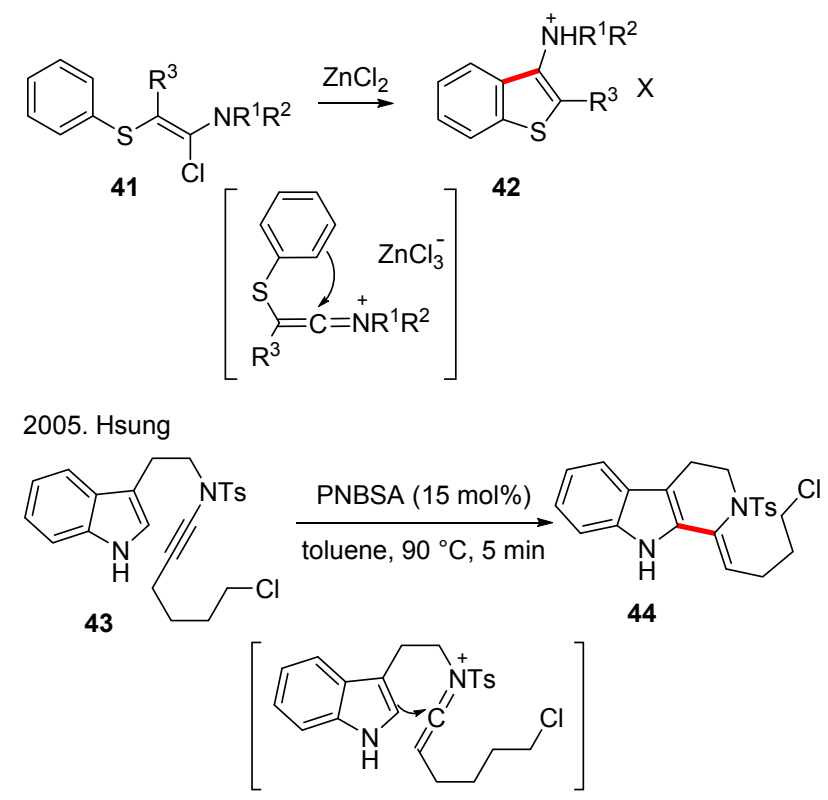

2014-2015. De Mesmaeker

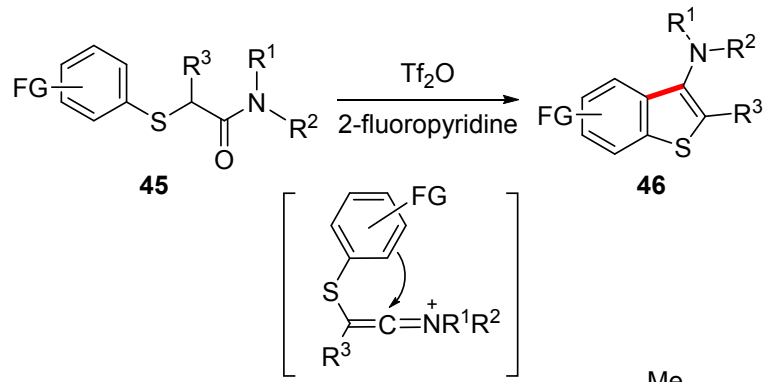<smiles>C=Cc1ccccc1CC(=O)N(C)C[13C](=O)[O-]</smiles><smiles>C[N+](C)=C1C=Cc2ccccc21</smiles>

2015. Takasu

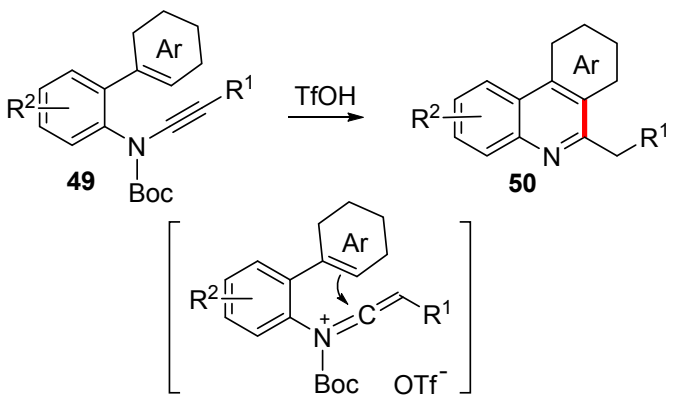

图式 11 烯酮亚胺盐引发的亲电环化反应

Scheme 11 keteniminium salts initiated electrophilic cyclizations

1967 年 Oth 与 Viehe 等 ${ }^{[30]}$ 报道了首例烯酮亚胺盐参

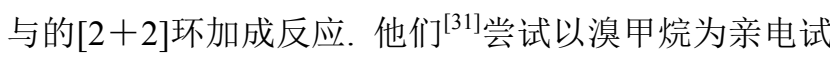


剂与炔胺 51 反应制备烯酮亚胺盐 52 , 意外发现所形成 的烯酮亚胺盐在反应体系中与炔胺发生 $[2+2]$ 环加成反 应, 生成少量的环加成产物 54, 同时伴有 $N$-烷基化产物 55 的生成(Scheme 12). 此后, Viehe 与 Ghosez 等 ${ }^{[31]}$ 以酰 胺为原料单独制备烯酮亚胺盐 56, 避免了以炔胺制备 烯酮亚胺盐过程中的副反应, 使之与炔胺 57 反应, 得到 了较高产率的分子间[2+2]环加成产物 $\mathbf{5 8}$ (Eq. 5).

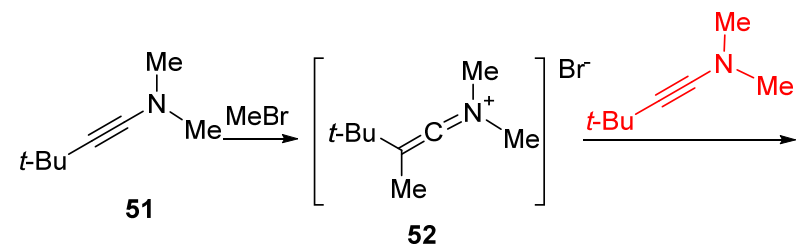

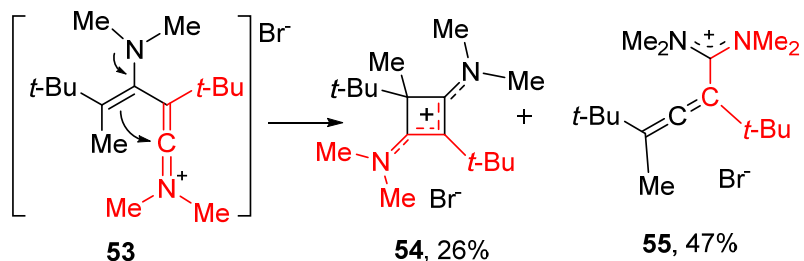

图式 12 烯酮亚胺盐参与环加成反应的发现

Scheme 12 Discovery of cycloaddition reaction of keteniminium salts

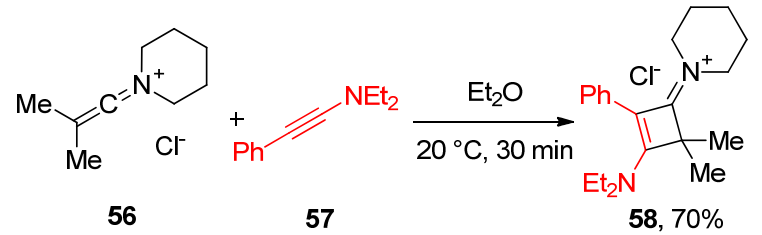

1972 年, Ghosez 等 ${ }^{[23,32]}$ 发现上述烯酮亚胺盐与普通 烯烃的碳碳双键也可发生分子间 $[2+2]$ 环加成反应. 这 一发现极大地推动了烯酮亚胺盐化学的发展. 他们以 $\mathrm{AgBF}_{4}$ 活化 $\alpha$ 氯代烯胺 59, 得到的烯酮亚胺盐 60 与烯 烃发生 $[2+2]$ 环加成反应, 得到了较高收率的环丁亚胺 盐 61 (Scheme 13).

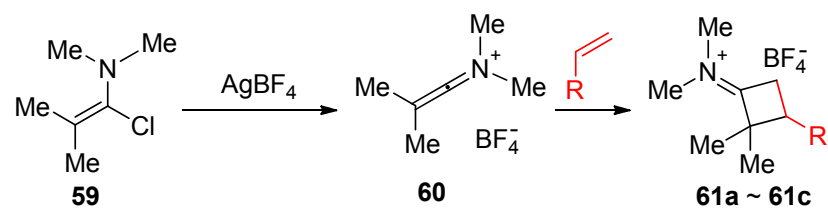<smiles>C=CC1CC(=[N+](C)C)C1(C)C</smiles>

$61 \mathrm{a}, 84 \%$

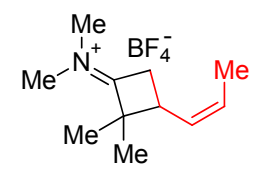

61b, $85 \%$

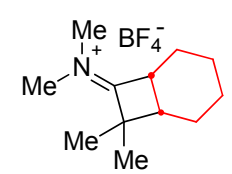

61c, $83 \%$
图式 13 烯酮亚胺盐与烯烃发生 $[2+2]$ 环加成反应 Scheme 13 Cycloaddition reaction of keteniminium with olefins

1981 年, Ghosez 等 ${ }^{[12,33]}$ 又提出以三氟甲基磺酸酐
$\left(\mathrm{Tf}_{2} \mathrm{O}\right)$ 与 $2,4,6$-三甲基吡啶 $(2,4,6$-Collidine)的亲电体系, 活化酰胺制备烯酮亚胺盐原位与烯烃或炔烃发生环加 成反应制备环丁酮衍生物 66. 这一制备烯酮亚胺盐的 方法，避免使用毒性较大的光气，且原料简单易得，成 为后续制备烯酮亚胺盐的常用方法(Scheme 14). 但值 得注意的是该方法制备的高活性烯酮亚胺盐 64 难以分 离纯化，通常与反应体系中其他反应物直接作用生成产 物.<smiles>[R]CCCCCC[R]([R20])([H])C[R]</smiles>

66a, $60 \%$ (cis + trans)<smiles>O=C1C[C@H](c2ccccc2)[C@@H]1c1ccccc1</smiles>

$66 \mathrm{~b}, 65 \%$

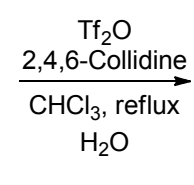

$\mathrm{R}^{3} \mathrm{R}^{1} \mathrm{R}^{2}$ $\overbrace{\mathrm{H}_{2} \mathrm{O}}^{66 \mathrm{a} \sim 66 \mathrm{~d}}$

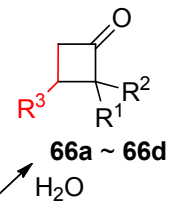<smiles>[R3]C1CC(=[N+](C)C)C1([R])[R]</smiles>

65<smiles>O=C1CCC1Pc1ccccc1</smiles>

$66 c, 35 \%$

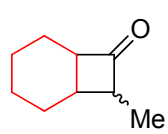

$66 \mathrm{~d}, 48 \%$ ( 2 isomers)
图式 14 由烯酮亚胺盐制备环丁酮衍生物

Scheme 14 Synthesis of cyclobutanones from keteneminium salts

1982 年, Ghosez 等 ${ }^{[34]}$ 报道了利用三氟甲基磺酸酤 与 2,4,6-三甲基吡啶的亲电体系活化手性酰胺，实现手 性吡咯烷诱导的不对称 $[2+2]$ 环加成反应. 该反应中, 手性酰胺 67 在亲电活化后形成相应的手性烯酮亚胺盐, 随后与环戊烯发生环加成反应，最后水解得到对映体过 量的环丁酮衍生物 69 (Scheme 15). 另外, 作者还发现 $\beta$-二取代的烯酮亚胺盐与环戊烯发生 $[2+2]$ 环加成反应, 水解后可得更高非对映异构的环丁酮 71. 但他们并未 给出更大范围的底物反应结果(Scheme 15).<smiles>COC[C@H]1CCCN1C(C)=O</smiles><smiles>[C+]1C=CCC1</smiles>

67<smiles>COC[C@H]1CCCN1C(Cl)=C(C)C</smiles>

70

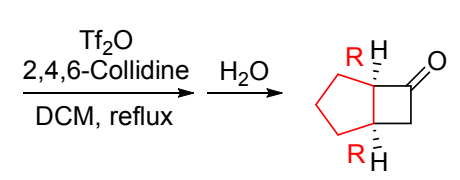

69, $30 \%, 92 \%$ ee

图式 15 不对称 $[2+2]$ 环加成反应合成手性环丁酮 Scheme 15 Asymmetric [2+2] cycloaddition towards synthesis of enantiomer enriched cyclobutanones 
手性辅基诱导的烯酮亚胺盐与烯烃的不对称 [2+2] 环加成反应被应用于一系列生物活性分子及药物中间 体的合成, 如 $( \pm)$-Asarinin (72)、( \pm )-Epimagnolin A

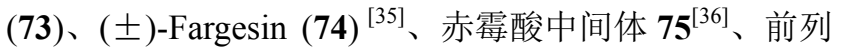
腺素内酯(76) ${ }^{[37]}$ 及 3 -酰基取代的环丁酮螺环化合物 $77^{[38]}$ (图 2).<smiles>[Y20]C1CC2OC[C@H]2[C@H]1[Y20]</smiles>

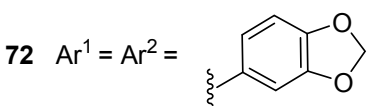<smiles>COc1ccc(I)cc1I</smiles>

74<smiles>[Y19]=Cc1ccc2c(c1)OCO2</smiles><smiles>COc1ccc(I=[W]#N)cc1OC</smiles>

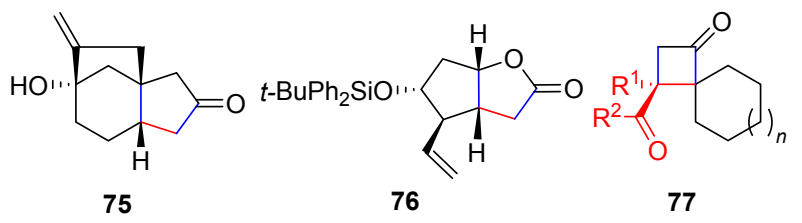

图 2 烯酮亚胺盐环加成反应的应用

Figure 2 Applications of keteniminium involved cycloaddition reactions

最近, De Mesmaker 等 ${ }^{[39]}$ 以 $N$-烯丙基取代酰胺 78 为底物, 通过与烯烃的 $[2+2]$ 环加成反应, 合成了环丁 基亚胺阳离子 80, 进一步还原、烯丙基脱保护, 成功制 备一系列环丁基胺衍生物 81 (Eq. 6).<smiles>[R]C([R])=CC=CCN(CC=C)C(=O)C([R])[R]</smiles>

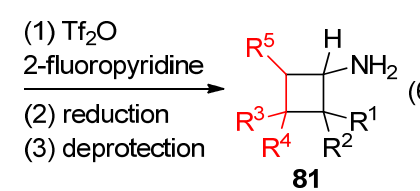

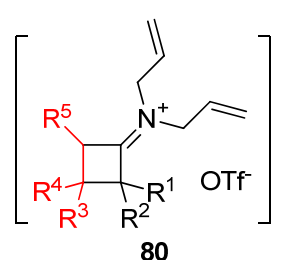

除了烯烃以外, 烯酮亚胺盐也可以与炔烃发生 $[2+$ 2]环加成反应. De Mesmaker 和 Sulzer-Mossé 等 ${ }^{[40]}$ 详细 研究了此类反应. 他们同样利用三氟甲磺酸酐/2,4,6-三 甲基吡啶对酰胺 82 进行亲电活化, 制备的烯酮亚胺盐 与端炔 83 发生 $[2+2]$ 环加成反应, 得到的环丁烯亚胺 84 可与环戊二烯发生 Diels-Alder (D-A)反应, 立体专一地 给出 exo 型环加成产物 85 (Scheme 16). 最近, Domingo 等 ${ }^{[41]}$ 又以密度泛涵(DFT)理论对烯酮亚胺盐与端炔的 $[2+2]$ 环加成反应进行了理论计算研究.

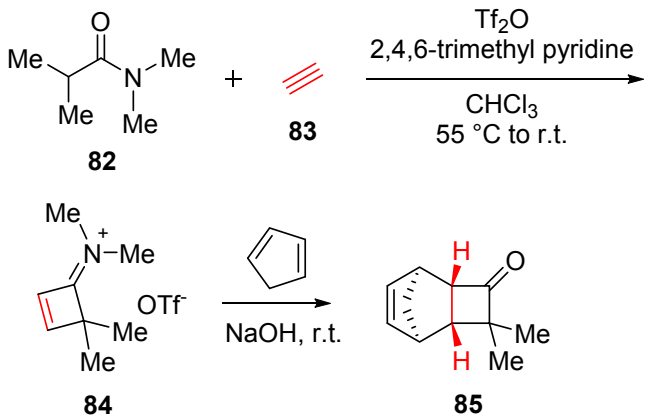

图式 16 环丁烯酮亚胺盐的制备及其 D-A 反应

Scheme 16 Synthesis of cyclobuteniminium salts followed its Diels-Alder reactions

2011 年, Takasu 等 ${ }^{[42]}$ 报道了炔酰胺与醛亚胺在双三 氟甲基磺酰亚胺 $\left(\mathrm{Tf}_{2} \mathrm{NH}\right)$ 或樟脑磺酸 $(\mathrm{CSA})$ 作用下生成 $\alpha, \beta$-不饱和脒的反应. 炔酰胺 $\mathbf{8 6}$ 与醛亚胺 87 在 Brønsted 酸作用下首先生成氮杂环丁烯中间体 $\mathbf{8 8}$, 然后开环生 成 $\alpha, \beta$-不饱和脒 89. 他们发现该反应可以通过催化剂及 溶剂的选择调整氮杂环丁烯 88 的开环方向, 实现 $\alpha, \beta-$ 不饱和朕的立体选择性合成. 在极性溶剂中利用双三氟 甲基磺酰亚胺, 有助于生成反式的 $\alpha, \beta$-不饱和脒; 在非 极性溶剂中利用樟脑磺酸, 有助于生成顺式的 $\alpha, \beta$-不饱 和脒(Scheme 17).

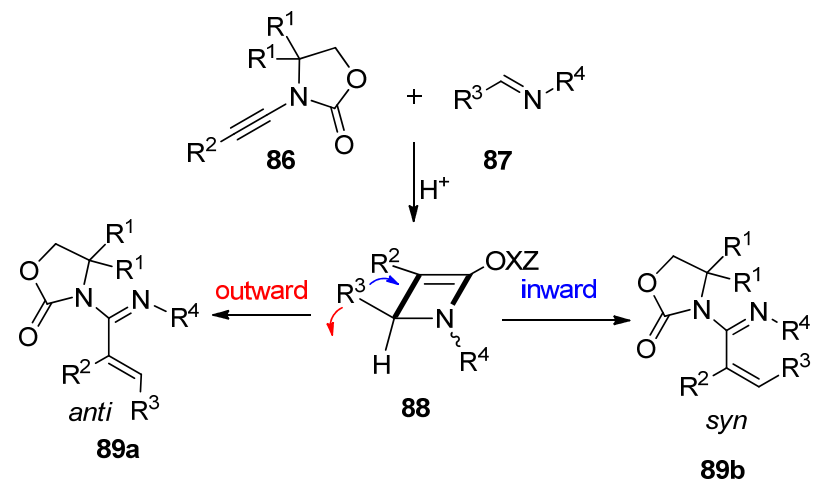

图式 17 炔酰胺与醛亚胺合成 $\alpha, \beta$-不饱和榺

Scheme 17 Synthesis of $\alpha, \beta$-unsaturated amidine using ynamides and aldimines

\section{4 亲电重排反应}

1966 年, Ficini ${ }^{[43]}$ 首次报道了三氟化硼促进的炔胺 与烯丙醇的 Claisen 重排反应, 制备 $\alpha$-烯丙基酰胺(Eq. 7). 该反应中, 三氟化硼作为 Lewis 酸与烯丙醇的氧原 子配位，提高了烯丙醇的酸性，被释放的质子酸将炔胺 90 转换为烯酮亚胺盐, 随后烯丙醇对烯酮亚胺盐进行 亲核加成构建烯酮 N,O-缩醛中间体 92, 最后经过 Claisen 重排得到 $\alpha$-烯丙基化的酰胺 93. 该重排反应也 被称为 Ficini-Claisen 重排反应(Eq. 7). 


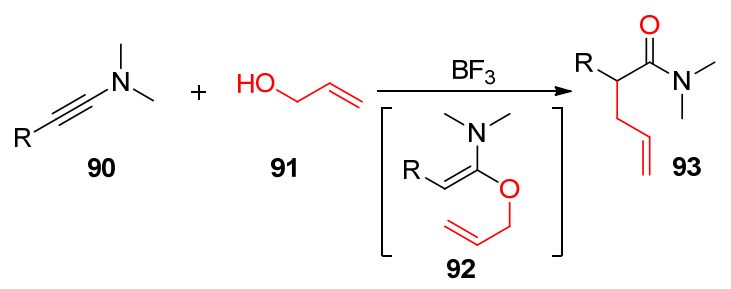

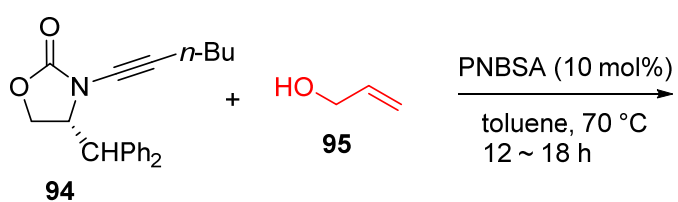

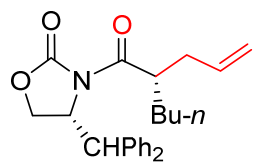

(8)

96, 70\%, $d r=96 / 4$ PNBSA: para-nitrobenzenesulfonic acid

由于炔胺自身不稳定, Ficini-Claisen 重排反应的发 展和应用受到很大限制. 2002 年, Hsung 课题组 ${ }^{[44]}$ 提出 以更稳定的炔酰胺替代炔胺, 并进一步利用 Evans 手性 辅基, 实现了不对称的 Ficini-Claisen 重排反应(Eq. 8). 他们发现, Brønsted 酸的酸性对该反应有着重要影响. 以对甲苯磺酸为催化剂, 反应需要在较高温度下进行, 且反应产率极低，大部分炔酰胺原料发生了水合反应. 以对硝基苯磺酸为催化剂, 反应可以降到 $70{ }^{\circ} \mathrm{C}$ 并给出 较高产率的重排产物, 立体选择性地生成顺式异构体 96. 反应可能的机理: 首先, 在对硝基苯甲酸的作用下, 炔酰胺 97 质子化生成烯酮亚胺盐 98, 烯丙醇对其亲核 进攻生成 $E$ 式的烯酮 N,O-缩醛胺中间体 99, 接着在手 性辅基的诱导下完成不对称的 Ficini-Claisen 重排反应 (Scheme 18).

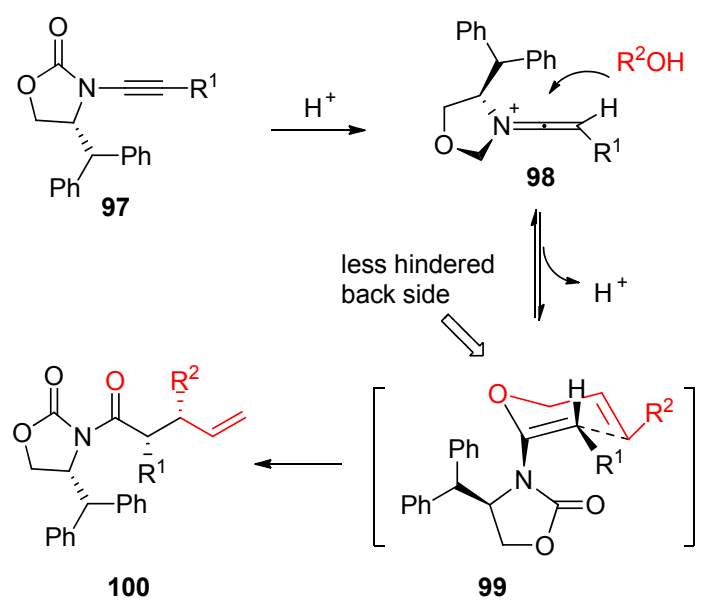

图式 18 Ficini-Claisen 重排反应可能机理 Scheme 18 Proposed mechanism for Ficini-Claisen rearrangement
2010 年, Maulide 课题组 ${ }^{[45]}$ 拟设计酰胺烯丙基醚 $\mathbf{1 0 1}$ 经由烯酮亚胺盐中间体与端烯的分子内 $[2+2]$ 环加成反 应, 合成环丁酮 104, 但意外地得到了 $\alpha$-烯丙基化的环 戊内酯 105 (Scheme 19). 反应可能的机理: 首先是酰胺 在 Ghosez 开发的亲电体系中形成烯酮亚胺盐, 接着烯 丙基醚中氧原子对烯酮亚胺盐亲核进攻形成乙烯基烯 丙基氧鎓离子中间体 107, 再经 Claisen 重排给出 $\alpha$-烯丙 基亚胺阳离子 108, 最后水解得到环戊内酯 $\mathbf{1 0 5}$.

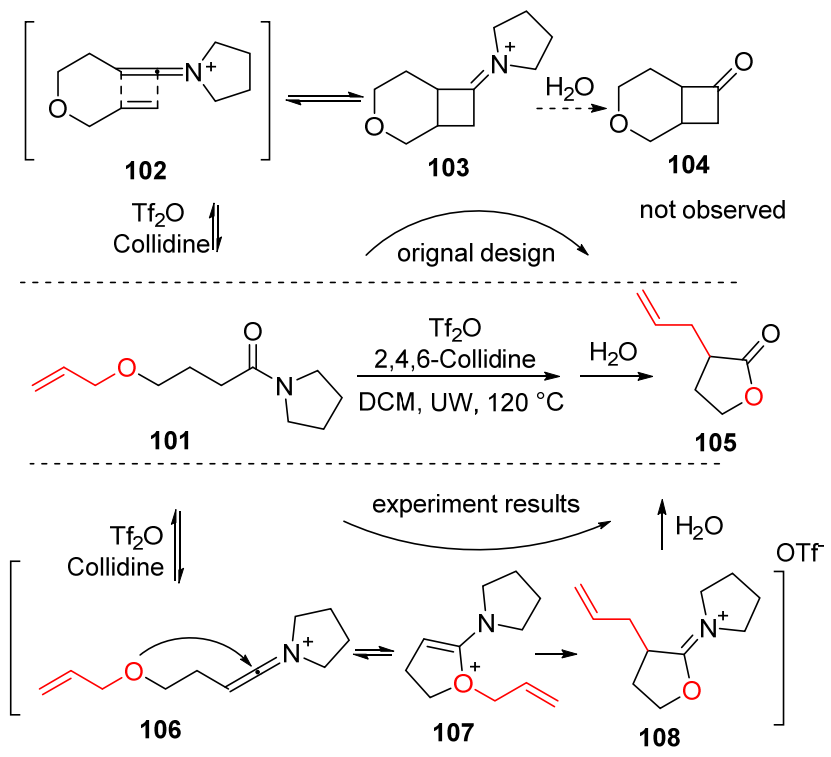

图式 19 环化/Claisen 重排反应的意外发现

Figure 19 Unexpected discovery of cyclization/Claisen rearrangement

随后的研究发现, 除烯丙基以外, 其他能够稳定碳 正离子的取代基如炔丙基、茮基、2-四氢呋喃基、2-四 氢吡喃基等都能参与上述亲电重排反应, 制备一系列 $\alpha-$ 烷基取代的内酯化合物 ${ }^{[45,46]}$ (Scheme 20).

上述亲电重排反应形成的亚胺阳离子 108 具有一定 稳定性，可以从反应液中分离出来，其结构也由单晶表 征并确定(Eq. 9). 亚胺阳离子 108 与不同亲核试剂反应 表现出不同的选择性. 强的硬亲核试剂如 $\mathrm{H}_{2} \mathrm{O} 、 \mathrm{NaBH}_{4}$ 主要进攻该亚胺阳离子的 $\mathrm{C}(1)$, 而软亲核试剂或相对弱 亲核试剂会进攻 $\mathrm{C}(4)$, 同时伴随 $\mathrm{C}-\mathrm{O}$ 键的断裂, 实现 远程 $\mathrm{C}-\mathrm{O}, \mathrm{C}-\mathrm{S}, \mathrm{C}-\mathrm{N}, \mathrm{C}-\mathrm{P}$ 或 $\mathrm{C}-\mathrm{C}$ 键的构建 ${ }^{[47]}$ (Scheme 21).

研究还发现，若将烯丙基换成苄基，以酰胺茮醚 113 为底物, 经亲电重排反应可以得到含有季碳中心的 脱芳构化产物 114 (Scheme 22). 该反应有两种可能的机 理. 第一种可能机理(path a), 酰胺在亲电试剂作用下形 成烯酮亚胺盐，随后茮基醚亲核进攻烯酮亚胺盐得到中 间体 114, 此中间体可能通过茮基的 1,5- $\sigma$ 迁移，直接得 到产物 115; 另一种可能的机理(path b), 以同样的过 


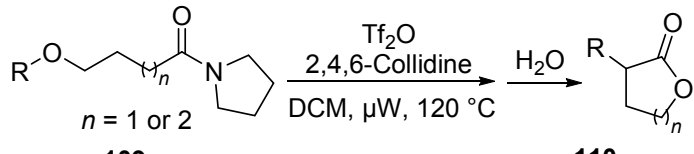

109<smiles>C=CCC1CCOC1=O</smiles>

$90 \%$<smiles>C=CCC1(C)CCOC1=O</smiles><smiles>C=C1CCCC[C@H]1C1CCOC1=O</smiles>

$48 \%, \operatorname{dr} 9: 1$<smiles>C=C(C)C1CCOC1=O</smiles><smiles>C=C=C([Hg]Cl)C1CCOC1=O</smiles>

$76 \%$<smiles>C=CC(C)C1CCCOC1=O</smiles>

$40 \%$<smiles>[R]c1ccc(C)c(C2CCOC2=O)c1</smiles><smiles>CC(=O)Cc1ccccc1C1CCOC1=O</smiles><smiles>O=C1OCCC1C1CCCO1</smiles><smiles>CC1(C2CCCCO2)CCOC1=O</smiles>

$60 \%$, dr $57: 43$<smiles>C=CCOCCCC(=O)N1CCCC1</smiles>

101

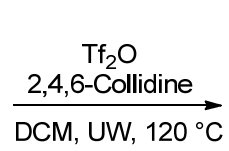

$\overrightarrow{D C M}, \mathrm{UW}, 120^{\circ} \mathrm{C}$<smiles>CCC1CCOC1=N</smiles>

isolated fully characterized<smiles>C=CCC1CCOC1=N</smiles>

图式 21 亚胺阳离子 108 与各类亲核试剂的反应

Figure 21 Iminium ether 108 captured by various nucleophiles 应重新进行设计，尝试将底物 117 中烯丙基醚部分从酰 胺羰基一侧转移至胺基一侧, 得到酰胺底物 118. 不难 推测，此新设计的底物通过亲电重排可能实现酰胺 $\alpha$ 位 的烯丙基化. 进一步观察, 底物 118 具有氨基醇的结构 单元, 若引入手性氨基醇, 便得到含手性酰胺的底物 119, 该手性酰胺通过亲电重排反应有可能实现酰胺 $\alpha$ 位的不对称烯丙基化(Scheme 23).

经过手性氨基醇的笁选，他们 ${ }^{[48]}$ 确定采用伪麻黄 碱链接羰基与烯丙基单元，得到底物 120, 实现预想中 的 $\alpha$-不对称烯丙基化反应. 进一步研究发现，产物中的 手性辅基部分可以通过水解或还原水解去除, 生成相应 的 $\alpha$-烯丙基化的羧酸衍生物 121 和 $\alpha$-烯丙基化的脂肪醛 122. 反应表现出非常好的官能团兼容性. 一些传统 $\alpha$ 烷基化方法无法兼容的碱性敏感的官能团(如端炔、含 $\alpha$-氢的酮、酯、卤代烷等)对该反应都没有明显的影响

2013 年 Maulide 等 ${ }^{[48]}$ 对酰胺烯丙基醚的亲电重排反

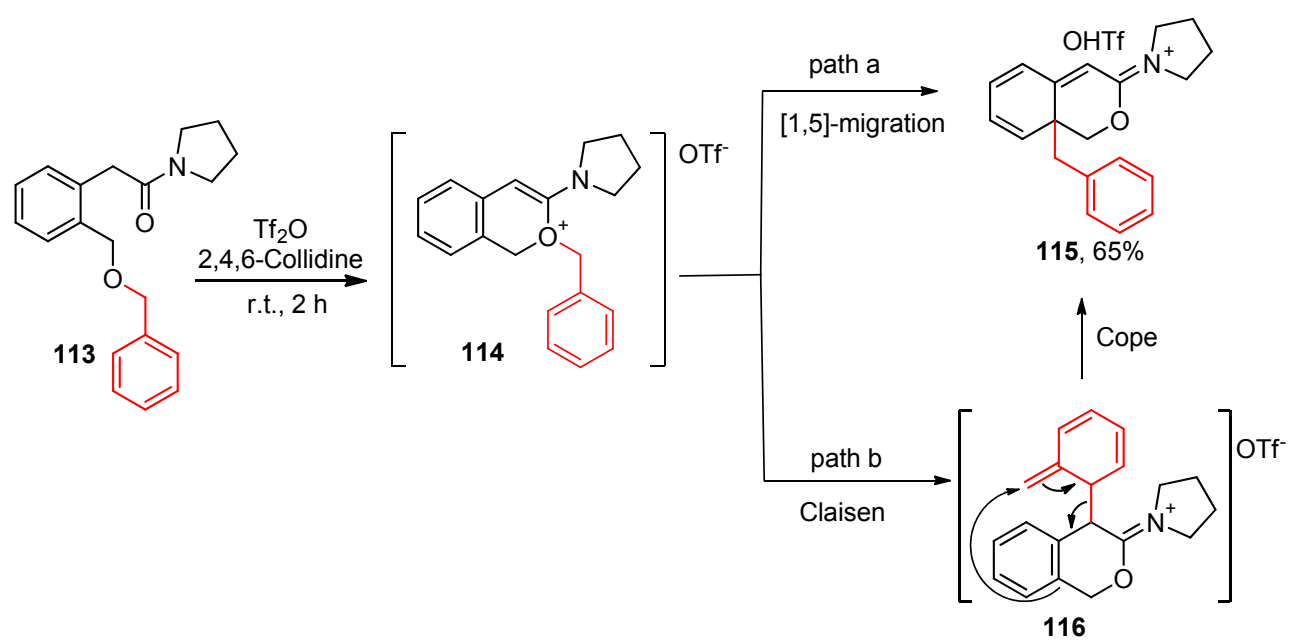

图式22 酰胺113亲电重排反应实现苯环的脱芳构化

Scheme 22 Dearomatization of benzene via electrophilic rearrangement of amide $\mathbf{1 1 3}$ 
<smiles>[R]CCC(=O)N(C)CCOCC=CC=C</smiles><smiles>[R]CCC(=O)N(C)c1ccc(OCC=CC)cc1</smiles>

图式 23 不对称 $\alpha$-烯丙基反应的设计思路

Scheme 23 Design of asymmetric $\alpha$-allylation

(Scheme 24).

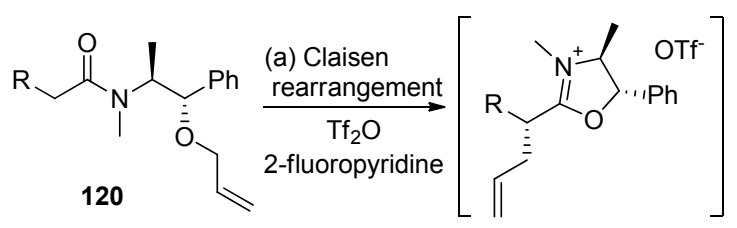<smiles>[Y12]CCC([R])C(=O)C=CC(=C)CC([R])C(=O)O</smiles>

selected examples:

in situ hydrolysis to carboxylic acids<smiles>C#CCC[C@H](CC=C)C(=O)O</smiles><smiles>C=CC[C@H](NCC(=O)Pc1ccccc1)C(=O)O</smiles>

121a, $75 \%, 88 \%$ ee

121b, $47 \%, 94 \%$ ee $121 c, 80 \%, 95 \%$ ee

in situ reduction/hydrolysis to aldehydes<smiles>C#CCC[C@H](C=O)CC=C</smiles><smiles>C=CCCCCCC(=O)OC</smiles><smiles>C=CCC(C=O)CBr</smiles>

122a, $52 \%, 90 \%$ ee

122b, $82 \%, 90 \%$ ee

122c, $50 \%, 90 \%$ ee

图式 24 基于手性酰胺亲电重排的不对称 $\alpha$-烯丙基化反应

Scheme 24 Asymmetric $\alpha$-allylation through electrophilic rearrangement of chiral amides

有意思的是, 同样采用 $(1 S, 2 S)$-伪麻黄碱为手性辅 基, 合成 Myers 不对称烷基化的底物 123 和亲电重排底 物 124. 含同一辅基的两个酰胺底物, 经过 Myers 烷基 化反应得到的产物 125 为 $R$ 构型, 而亲电重排反应得到 的产物 126 为 $S$ 构型. 反应的立体选择性解释如 Scheme 25 所示.

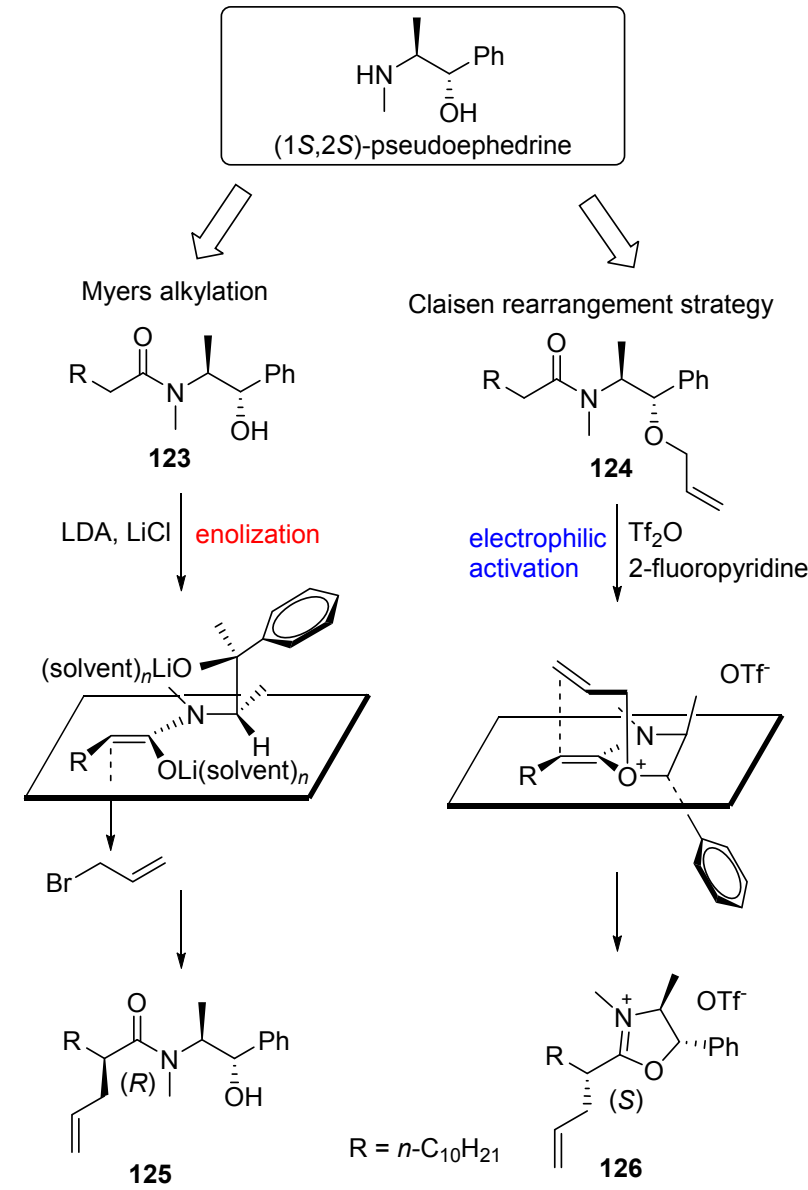

图式 25 Myers 不对称烷基化与亲电重排反应 Scheme 25 Myers alkylation vs electrophilic rearrangement

在手性酰胺亲电重排反应的研究中, Maulide 等 ${ }^{[49]}$ 发现三氟甲基磺酸䣶/2-氟代吡啶的亲电体系能够大幅 提高重排反应的效率, 使得传统的 Ghosez 亲电体系难 以促进的重排反应能够在低温下进行 $\left(0{ }^{\circ} \mathrm{C}\right)$. 由此设想, 这一新型酰胺亲电活化体系能否应用到普通酰胺的亲 电活化中，高效制备烯酮亚胺盐 128 (Scheme 26). 


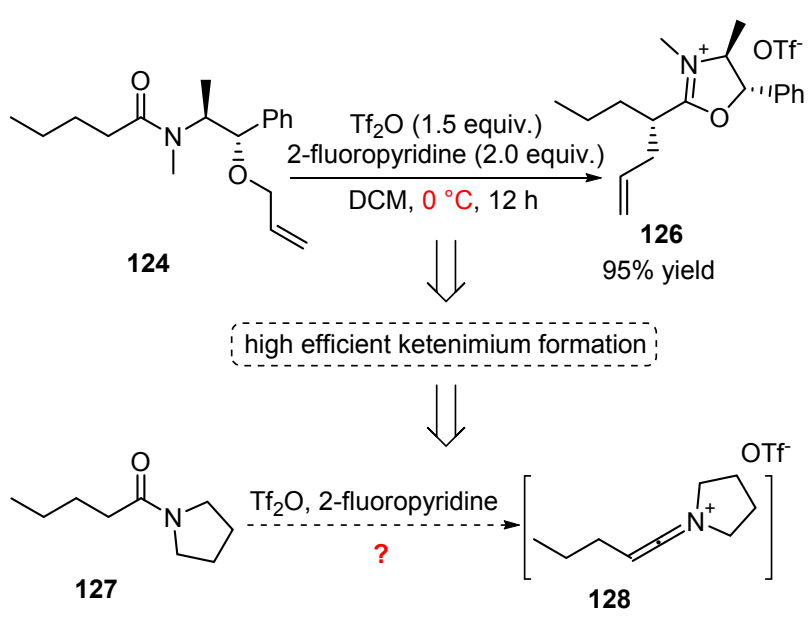

图式 26 高效酰胺亲电活化体系应用于新反应设计 Scheme 26 High efficient electrophilic activation systems applied to a new reaction design

传统 Ghosez 法制备烯酮亚胺盐需要在引入亲电试 剂三氟甲基磺酸酐之前加入烯烃或其他亲核试剂, 其目 的是为了高温条件下生成的烯酮亚胺盐能迅速与反应 体系中的烯烃或其他亲核试剂反应, 从而避免自身的分 解, 因此 Ghosez 法无法单独制备烯酮亚胺盐. 这样也导 致对亲电试剂敏感的亲核试剂无法被引入到与烯酮亚 胺盐的反应中, 限制了烯酮亚胺盐反应的发展. 因此, 开发单独制备高活性烯酮亚胺盐的方法, 将建立一个活 性中间体平台, 为拓宽与烯酮亚胺盐反应的亲核试剂的 范围创造了条件.

经过大量条件优化后, Maulide 等 ${ }^{[49]}$ 并没能成功地 将酰胺 127 转换为预期的烯酮亚胺盐 128, 但发现三氟
甲基磺酸酐/2-碘代吡啶的亲电体系能有效地将酰胺 127 转换成烯胺吡啶盐 129 (Scheme 27). 进一步研究发现, 烯胺吡啶盐 129 具有非常高的亲电性, 能够与二苯基亚 砜反应，通过亲电重排实现酰胺的 $\alpha$-芳基化. 该 $\alpha$-芳基 化反应的底物适用性非常好，含有氯代烷基、芳基、酯 基或烷基酮的酰胺都能顺利地参与亲电重排反应 (Scheme 28). 依据核磁的表征以及原位红外光谱对反应 的跟踪研究, 他们推测, 酰胺在亲电活化后形成烯胺吡 啶盐 129 与烯酮亚胺盐 128 产生平衡, 亲核试剂二苯基 亚砜可以与烯酮亚胺盐 128 反应得到 $N, O$-烯酮中间体 133 , 经脱芳构化重排以及恢复芳香性制备 $\alpha$-苯基取代 的酰胺产物 130 (Scheme 29).

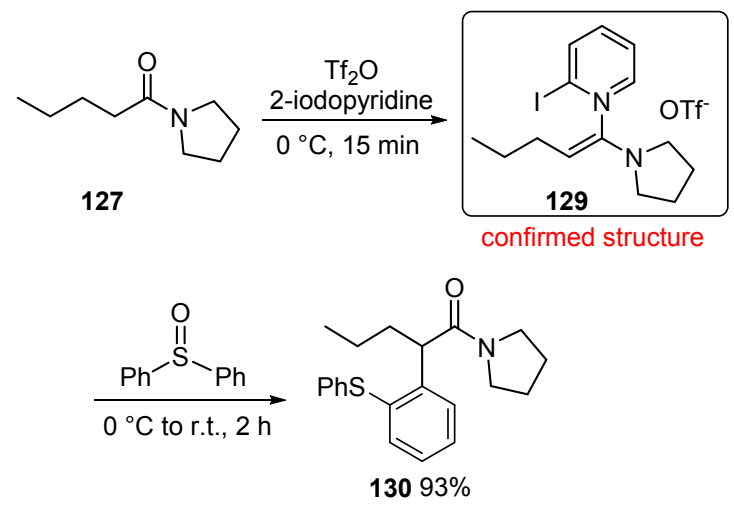

图式 27 酰胺 128 的 $\alpha$-芳基化反应

Scheme 27 Direct $\alpha$-arylation of amide 128

在上述酰胺 $\alpha$-芳基化研究的启发下, Maulide 等 ${ }^{[49,50]}$ 提出以质子酸活化炔酰胺的方式替代酸酐等亲电试剂 活化酰胺的方式来构建烯酮亚胺盐中间体，再与芳基亚

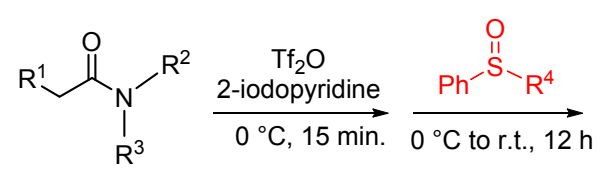

131<smiles>[R]Sc1ccccc1C([R])C(=O)N([R])[R]</smiles>

$132 \mathrm{a} \sim 132 \mathrm{~g}$

Selected examples<smiles>O=C(Cc1ccccc1SP)N1CCCC1</smiles>

132a $50 \%$<smiles>O=C(NCCCl)C(c1ccccc1)c1ccccc1P</smiles>

132b $71 \%$<smiles>CN(C)C(=O)c1ccccc1P</smiles>

132c $60 \%$

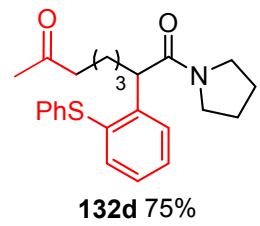<smiles>COC(=O)CCC(=O)N1CCCC1</smiles>

$132 \mathrm{e} 84 \%$<smiles>COC(=O)CCCC(C(=O)N1CCCCC1)c1ccccc1P</smiles>

$132 f 78 \%$<smiles>CCCC(C(=O)N1CCCC1)c1ccccc1SC</smiles>

132g 83\%

图式 28 酰胺的 $\alpha$-芳基化反应

Scheme 28 Substrate scope for direct $\alpha$-arylation of amides 


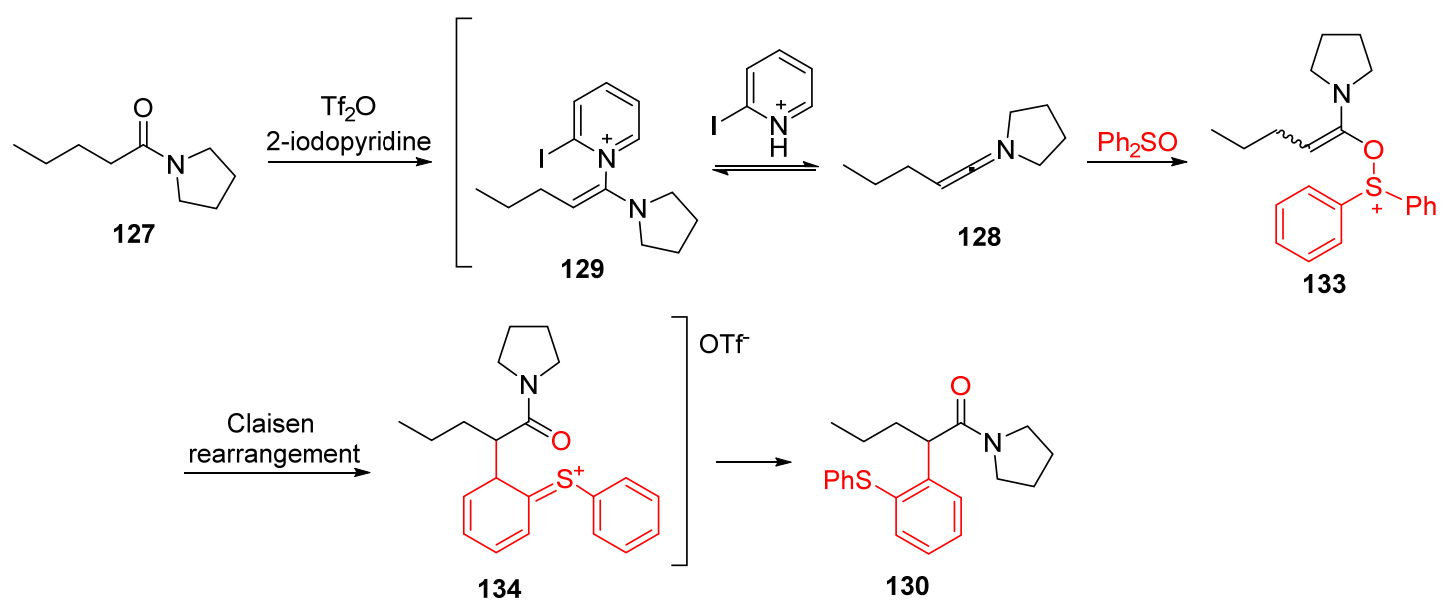

图式 29 酰胺的 $\alpha$-芳基化的可能机理

Scheme 29 Proposed reaction mechanism for $\alpha$-arylation of amides

砜反应实现炔酰胺的氧化芳基化(Scheme 30). 这样的设 计使得该反应避免使用先前反应需要的反应量亲电试 剂, 且反应中没有副产物生成, 因而反应具备绿色、原 子经济的特点. 实验表明, 催化量的三氟甲磺酸便可实 现这一炔酰胺氧化芳基化的过程 ${ }^{[50]}$. 同时该反应也表现
出了预期的特点：(1)反应条件温和，室温即可反应；(2) 反应效率高, 通常反应在 $1 \mathrm{~h}$ 内完成; (3)无论是炔酰胺 还是芳基亚砜，底物的适用性都非常好; (4)反应具备优 良的官能团兼容性，氧基、酯基或烷氧基等官能团对反 应都没有显著影响(Eq. 10).

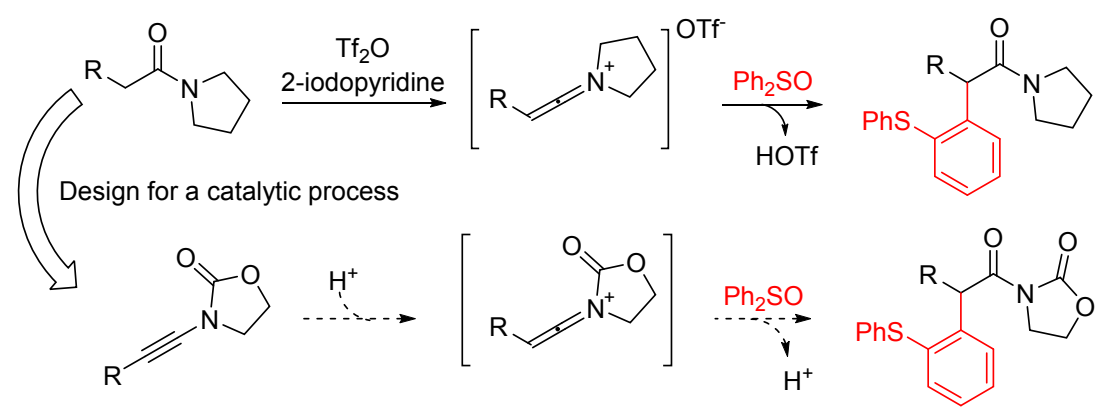

图式 30 质子酸催化的氧化还原芳基化反应的设计

Scheme 30 Design for a Brønsted acid catalyzed redox arylation reaction<smiles>[R]C#CN1CCOC1=O</smiles>

135

Selected examples<smiles>O=C1OCCN1C(=O)C(c1ccccc1)c1ccccc1S</smiles>

137 a, $53 \%$<smiles>[R6][R1]1ccc(S([R])=O)cc1</smiles>

1362.0 equiv.

$$
\underset{\text { DCTf }(10 \mathrm{~mol} \%)}{\longrightarrow}
$$$$
\text { r.t., } 0.5 \sim 1 \mathrm{~h}
$$<smiles>[R]C(C(=O)N1CCCO1)c1ccccc1P</smiles>

137<smiles>N#CCCCC(CCC#N)c1ccccc1P</smiles>

137b, $85 \%$<smiles>COC(=O)CCCC(C(=O)N1CCCO1)c1ccccc1S</smiles>

137c, $83 \%$<smiles>COCC(C(=O)N1CCOC1=O)c1ccccc1O</smiles>

$137 d, 87 \%$<smiles>CCCCC(C(=O)N1CCOC1=O)c1cc(C)ccc1Sc1ccc(C)cc1N</smiles>

137e, $60 \%$<smiles>CSc1ccccc1C([14CH3])C(=O)N1CCOC1=O</smiles>

137f, $86 \%$ 
对于不对称的 $\alpha$-芳基化, Maulide 等 $^{[50]}$ 也作了初步 探索. 通过在炔酰胺底物中引入手性啞唑烷酮, 可以实 现 Brønsted 酸催化非对映选择性 $\alpha$-芳基化反应(Eq. 11). 尽管反应的立体选择性不高, 但此初步试验结果证实了 手性辅基能够对该类反应起到不对称诱导的作用, 为不 对称 $\alpha$-芳基化反应的提出了新的思路.

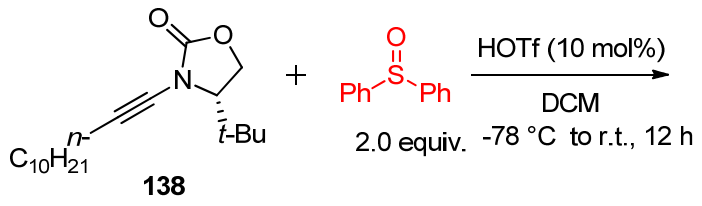<smiles>CCCCCC(C(=O)N1C(=O)OC[C@@H]1C(C)(C)C)c1ccccc1P</smiles>

$139,92 \%, d r=75: 25$

\section{4 总结与展望}

在过去 40 多年里, 烯酮亚胺盐化学得到了蓬勃的 发展. 其中, 烯酩亚胺盐的不对称 $[2+2]$ 环加成反应在 有机合成中已被广泛应用. 近年来利用烯酮亚胺盐亲电 重排发展的不对称 $\alpha$ 烯丙基化反应、酰胺 $\alpha$ 芳基化反应、 炔酰胺的氧化芳基化反应为烯酮亚胺盐化学提供了新 的发展思路. 我们认为未来烯酮亚胺盐化学还有以下发 展空间: (1)探索新型亲核试剂与烯酮亚胺盐的新反应模 式; (2)发展烯酮亚胺盐介入的多组分反应, 一步构建复 杂的杂、碳环化合物; (3)发展烯酮亚胺盐介入的不对称 反应，包括手性辅基诱导的不对称反应以及不对称催化 反应; (4)发展烯酮亚胺盐的形成方法, 为其相关反应的 发展提供支持. 我们相信, 原料简单易得、实验操作简 单、产物应用价值高的烯酮亚胺盐化学必将迎来更大的 发展.

\section{Reference}

[1] (a) Ye, J. T.; Ma, S. Acc. Chem. Res. 2014, 47, 989.

(b) Krause, N.; Winter, C. Chem. Rev. 2011, 111, 1994.

(c) Ma, S. Chem. Rev. 2005, 105, 2829.

(d) Allen, A. D.; Tidwell, T. D. Chem. Rev. 2013, 113, 7287.

(e) Lu, P.; Wang, Y. G. Chem. Soc. Rev. 2012, 41, 5687.

(f) Alajarin, M.; Marin-Luna, M.; Vidal, A. Eur. J. Org. Chem. 2012, 5637 .

(g) Lu, P.; Wang, Y. G. Synlett 2010, 165.

[2] Staudinger, H.; Meyer, J. Helv. Chim. Acta 1919, 619.

[3] (a) Xing, Y.; Cheng, B.; Wang, J.; Lu, P.; Wang, Y. G. Org. Lett. 2014, 16, 4814.

(b) Denmark, S. E.; Wilson, T. W. Angew. Chem., Int. Ed. 2012, 51, 9980.

[4] Alajarín, M.; Vidal, A.; Ortín, M. M. Org. Biomol. Chem. 2003, 1, 4282.

[5] (a) Amold, B.; Regitz, M. Angew. Chem., Int. Ed. 1979, 18, 320. (b) Alajarín, M.; Sánchez-Andrada, P.; Vidal, A.; Tovar, F. Eur. J. Org. Chem. 2004, 2636.

[6] (a) Molina, P.; Alajarín, M.; Vidal, A. J. Org. Chem. 1991, 56, 4008 (b) Yang, Y. Y.; Shou, W. G.; Chen, Z. B.; Hong, D.; Wang, Y. G. J. Org. Chem. 2008, 73, 3928.

[7] (a) Alajarín, M.; Bonillo, B.; Ortín, M. M.; Sánchez-Andrada, P.; Vidal, A. Org. Lett. 2006, 8, 5645.

(b) Alajarín, M.; Bonillo, B.; Sánchez-Andrada, P.; Vidal, A. Bautista, D. Org. Lett. 2009, 11, 1365.

[8] Snider, B. B. Chem. Rev. 1988, 88, 793.

[9] Dekorver, K. A.; Li, H.-Y.; Lohse, A. G.; Hayashi, R.; Lu, Z.-J.; Zhang, Y.; Hsung, R. P. Chem. Rev. 2010, 110, 5064.

[10] (a) Madelaine, C.; Valerio, V.; Maulide, N. Chem. Asian J. 2011, 6, 2224.

(b) Kaiser, D.; Maulide, N. J. Org. Chem. 2016, 81, 4421.

[11] Marchand-Brynaert, J.; Ghosez, L. J. Am. Chem. Soc. 1972, 94, 2869.

[12] (a) Charette, A. B.; Grenon, M. Can. J. Chem. 2001, 79, 1694.

(b) Xiao, K.; Wang, A.; Huang, P. Q. Angew. Chem., Int. Ed. 2012, $51,8314$.

(c) Bechara, W. S.; Pelletier, G.; Charette, A. B. Nat. Chem. 2012, 4, 228.

[13] Zificsak, C. A.; Mulder, J. A.; Hsung, R. P.; Rameshkumar, C.; Wei, L.-L. Tetrahedron 2001, 57, 7575.

[14] Rens, M.; Ghosez, L. Tetrahedron Lett. 1970, 11, 3765.

[15] Yashi, H.; Yorimitsu, H.; Oshima, K. Chem. Lett. 2008, 37, 40.

[16] Xu, S.-J.; Liu, J.-Q.; Hu, D.-H.; Bi, X.-H. Green. Chem. 2015, 17, 184.

[17] Compain, G.; Jouvin, K.; Martin-Mingot, A.; Evano, G.; Marrot, J.; Thibaudeau, S. Chem. Commun. 2012, 48, 5196.

[18] Métayer, B.; Compain, G.; Jouvin, K.; Martin-Mingot, A.; Bachmann, C.; Marrot, J.; Evano, G.; Thibaudeau, S. J. Org. Chem. 2015, 80, 3397.

[19] Tona, V.; de la Torre, A.; Padmanaban, M.; Ruider, S.; González, L.; Maulide, N. J. Am. Chem. Soc. 2016, 138, 8348.

[20] Tona, V.; Ruider, S. A.; Berger, M.; Shaaban, S.; Padmanaban, M.; Xie, L.-G.; González, L.; Maulide, N. Chem. Sci. 2016, 7, 6032.

[21] Theunissen, C.; Métayer, B.; Henry, N.; Compain, G.; Marrot, J.; Martin-Mingot, A.; Thibaudeau, S.; Evano, G. J. Am. Chem. Soc. 2014, 136, 12528.

[22] Lecomte, M.; Evano, G. Angew. Chem., Int. Ed. 2016, 55, 4547.

[23] Ghosez, L. Angew. Chem., Int. Ed. 1972, 11, 852.

[24] (a) Zhang, Y.-S. Tetrahedron Lett. 2005, 46, 6483. (b) Zhang, Y.-S. Tetrahedron 2006, 62, 3917.

[25] Ghosez, L.; Notte, P.; Bernard-Henriet, C.; Maurin, R. Heterocyles 1981, 15, 1179 .

[26] Zhang, Y.-S.; Hsung, R. P.; Zhang, X.-J.; Huang, J.; Slafer, B. W.; Davis, A. Org. Lett. 2005, 7, 1047.

[27] Lumbroso, A.; Behra, J.; Kolleth, A.; Dakas, P. Y.; Karadeniz, U.; Catak, S.; Sulzer-Mossé, S.; De Mesmaker, A. Tetrahedron Lett. 2015, 56, 6541.

[28] Villedieu-Percheron, J.; Catak, S.; Zurwerra, D.; Staiger, R.; Lachia, M.; De Mesmaker, A. Tetrahedron Lett. 2014, 55, 2446.

[29] Yamaoka, Y.; Yoshida, T.; Shinozaki, M.; Yamada, K.-I.; Takasu, K. J. Org. Chem. 2015, 80, 957.

[30] (a) Viehe, H. G.; Buijle, R.; Fuks, R.; Merényi, R.; Oth, J. M. F. Angew. Chem., Int. Ed. 1967, 6, 77.

(b) Viehe, H. G. Angew. Chem., Int. Ed. 1967, 6, 767.

[31] Ghosez, L.; Haveaux, B.; Viehe, H. G. Angew. Chem., Int. Ed. 1969, 8,454 .

[32] Marchand-Brynaert, J.; Ghosez, L. J. Am. Chem. Soc. 1972, 94, 2870 . 
[33] Falmagne, J.-B.; Escudero, J.; Taleb-Sahraoui, S.; Ghosez, L. Angew. Chem., Int. Ed. 1981, 20, 879.

[34] Houge, C.; Frisque-Hesbain, A. M.; Mockel, A.; Ghosez, L. J. Am. Chem. Soc. 1982, 104, 2920.

[35] Brown, R. C. D.; Bataille, C. J. R.; Bruton, G.; Hinks, J. D.; Swain, N. A. J. Org. Chem. 2001, 66, 6719.

[36] Shim, P.-J.; Kim, H.-D. Tetrahedron Lett. 1998, 39, 9517.

[37] Depré, D.; Chen, L.-Y.; Ghosez, L. Tetrahedron 2003, 59, 6797.

[38] O’Brien, J. M.; Kingsbury, J. S. J. Org. Chem. 2011, 76, 1662.

[39] Kolleth, A.; Lumbroso, A.; Tanriver, G.; Catak, S.; Sulzer-Mossé, S.; De Mesmaker, A. Tetrahedron Lett. 2016, 57, 2697.

[40] (a) Lumbroso, A.; Catak, S.; Sulzer-Mossé, S.; De Mesmaker, A. Tetrahedron Lett. 2014, 55, 5147.

(b) Lumbroso, A.; Catak, S.; Sulzer-Mossé, S.; De Mesmaker, A. Tetrahedron Lett. 2014, 55, 6721.

[41] Domigo, L. R.; Ríos-Gutiérrez, M.; Pérez, P. Tetrahedron 2015, 71, 2421
[42] Shindoh, N.; Kitaura, K.; Takemoto, Y.; Takasu, K. J. Am. Chem. Soc. 2011, 133, 8470 .

[43] Ficini, J. Tetrahedron Lett. 1966, 7, 6425.

[44] Mulder, J. A.; Hsung, R. P.; Frederick, M. O.; Tracey, M. R.; Zificsak, C. A. Org. Lett. 2002, 4, 1383.

[45] Madelaine, C.; Valerio, V.; Maulide, N. Angew. Chem., Int. Ed. 2010, 49, 1583.

[46] Valerio, V.; Madelaine, C.; Maulide, N. Chem. Eur. J. 2011, 17, 4742.

[47] Peng, B.; O'Donovan, D. H.; Jurberg, I. D.; Maulide, N. Chem. Eur. J. 2012, 18, 16292.

[48] Peng, B.; Geerdink, D.; Maulide, N. J. Am. Chem. Soc. 2013, 135, 14968.

[49] Peng, B.; Geerdink, D.; Farès, C.; Maulide, N. Angew. Chem., Int. Ed. 2014, 53, 5462.

[50] Peng, B.; Huang, X.-L.; Xie, L.-G.; Maulide, N. Angew. Chem., Int. Ed. 2014, 53, 8718.

(Qin, X.) 